\title{
Looking at Multilingual Competence as Reflected in Teenage Literature
}

\author{
Dwi Wulandari \\ \{sudarno_utomo@undip.ac.id\} \\ Universitas Diponegoro, Indonesia
}

\begin{abstract}
This study is looking at how multilingual competence can be reflected in teenager literature. Teenage literature is seen as a medium of interaction where the writers can deliver their ideas to the teen readers. With the assumption of what language mastered by the teenagers, the writers are working on the literature using language that are familiar to the readers. With the long range of time for English learning in Indonesia, it is assumed that the learners, the teenagers in particular, are in a particular stage of being multilingual speakers. By looking at two literature works with different time frames; Balada Si Roy: Joe [1] and Ruang Hampa Prada [2], this study shows the type of multilingual competence performed by the writers. It shows that most of the switching done by the writers are mostly in the forms of switching for expression and not necessarily showing the ability of being bilinguals. It also shows that media and global world are also giving influence in addition to the actual learning experience taking place in the classroom. It also reveals the different concept of identity formed by teenagers from different time frames.
\end{abstract}

Keywords: Multilingual Competence, Code Switching, Teenagers' Identity.

\section{Introduction}

In multilingual society, such as in Indonesia, we will be provided with so many language phenomena worth to study or merely to admire of. The complex situation of the culture contestation not only creates the dynamic life of culture, but it will also enable the people living in the culture to become multilinguals. In many cultures, the people have already started being bilingual since they are at a very young age, due to the fact that they are living in a bilingual society. Take a look at Indonesia for example. In most of the tribes in Indonesia, the people will speak two languages, i.e. their vernacular and the national language, Bahasa Indonesia. This holds true for most of the countries who set the national or official language different from the vernacular language.

With the advancement of globalization today, the addition of learning English in the world contributes to the more complex multilingual society. As one of the international languages, English is spoken by approximately 1.5 billion of the people in the world, and that counts for $20 \%$ of the whole population [3]. It is actually not the language with the largest population, however, what makes English astounding is the fact that less than a quarter of those speaking English are the native speakers, and more than $75 \%$ are speaking English as the second or foreign language. This suggests that English is spoken widely throughout the world. 
In Indonesia, English is also widely recognized as one means of communication. This is supported by the government's policy to include English in school's curriculum. Extra exposure of English through movies, TV series, and songs since the 1980s also adds support to the establishment of English in Indonesia.

At present, it is very common to find English utterances written or spoken in many media. Such utterances are becoming so common that it is not necessary to explain their meanings or to doubt of its correct usages. The utterances which can be found in the forms of words, phrase, clause, and other meaningful expressions are commonly found in novels written in Bahasa Indonesia. The use of such utterances in novel, especially those written for teenagers, or commonly known as teenage literature, shows interesting fact of the possibility of having multilingualism in English, because teenage literatures are written for teenagers and are mostly read by the teenagers as well. Hence, if the teenagers are able to shows ability in using English, it shows that the curriculum and the language exposure indeed help them to become multilinguals. Therefore, to gain such insight, this study is conducted to see whether such possibility can be detected in teenage literatures.

\section{Literature Review}

Many researches have worked on the issue of language contact through many different points of view. One of which is what is written by Sulistio [4] on the influence of English on the global world. One of his conclusions is that the more English is used globally, the more tendency is language shift to occur. This will create positive impact in the way that monolingual communication will trigger better development of many sectors in human interactions. However, the negative impact can also be seen from this fact. In the short term, this will create power inequality in the sense that those who master English will enjoy the privilege of accessing more convenience in working world. In the long run such condition will create the possibility of language death due to the fact that the language shifted will no longer be used and taught to the next generation. In this sense, English is also seen as the symbol of modernization [5], that the use of English is a signal of having modernized culture.

Hallen [6] particularly conducted a research on how Bahasa Indonesia phoneme changes under the influence of language contact. As multilingual society, Indonesian people are accustomed with the use of many languages including the use of foreign language such as English, Arabic, and Dutch in addition to the many vernacular languages. Those languages affect the use of some vocabulary in Bahasa Indonesia through borrowing system. Gradually such borrowing changes the phonemic system in Bahasa Indonesia as the phonemes need to be adjusted to the easiness of usage, although such borrowing has not yet created a multilingualism towards those languages.

\subsection{The Policy of English Learning in Indonesia}

English has been taught in certain schools in Indonesia since its independence. The policy to include English in schools' curriculum has begun since 1946, and it is legally supported by the Minister Decree No. 096/1967 stating that English is a compulsory course in secondary schools with the goal to equip the students with "working knowledge of English" [7]. In its development then the curriculum is focused on giving students competence in language skills; reading, writing, speaking, and listening skill. 
The four language skills shape the language competence integrated. In other words, the writing skill and the reading skill should develop hand in hand, and the ability to develop speaking skill is also quite dependent to the ability to develop listening skill. Although the four skills should be taught integrated, in practice, however, to put emphasis on teaching one of the skills, reading for example, will make the teaching method and its target quite easier [8].

The focus in teaching English skills in junior and high schools in Indonesia is not always in accordance with what is being targeted, due to the fact that the teaching method is heavily relied on reading activity and learning grammar. Speaking skill is mostly shaped through the activity of writing the conversation and not directly practicing it. Likewise, the writing activity is also targeted on the ability to write correct sentences, yet it is not necessarily to develop the students' ability to write longer paragraph nor even a short essay.

Many factors contribute to the difficulties in complying with what is being targeted in teaching English, one of which is teachers' ability especially during the early time of the establishment of English in the curriculum. Even though we can find good and qualified English teachers now days, it does not mean that all teachers teaching junior and high schools feel comfortable to teach speaking skill. The plenty numbers of students in one class, and the many classes to teach have become the hindrance for applying real communicative method. In such condition, the easiest way in teaching English is grammar translation method [9]. The inadequate facility to teach listening also adds to the problem so that listening skill is the most skill left being untaken care of.

Nevertheless, in many big cities in Indonesia there are many English courses offering learners to learn English particularly on the four language skills. These institutions have helped many learners to get better skills in using English. The fact that such institutions are able to hold many classes shows that there are a lot of people interested in learning English intensively.

\subsection{Multilingual Competence in Indonesia}

Bilingualism is the ability to use two languages. There are many levels in bilingualism, in the sense that the linguist has not yet come to a conclusion on how good ones can use both languages so that they can be called bilingual. Holmes [10] states that bilingual can be referred to those who can use two languages for communication purposes although they are not mastering both languages in the same levels.

Indonesian people can be said as being bilinguals even from the start as they are accustomed to use Bahasa Indonesia and their vernacular language for communication. The question is that whether they are, especially the teenagers, also considered as being multilinguals in English as well. With the long years of learning English in schools, and the exposure of English in many media as well as the participation in taking non formal English course, there is a high potential to make Indonesian people multilinguals [11].

\subsection{Teenage Literature}

Teenage literature is the literature work, mostly in the form of novel, written for teenagers. As it is written for teenagers, the language used and the story evolved in the novel are also in accordance with the teenagers' life. That is why since its first establishment in Indonesia, such novels gain a lot of popularity among teenagers [12].

The stories written in teenage novel can be various, although all of them characterize the problem faced by the teenagers such as, love, schools' life, love/hatred toward the parents, 
friendship, etc., which are written in many different genres including drama or science fictions. According to Kaplan [13] there are various interesting facts about teenage literature. First, teenage writers are showing to have high creativity in developing their stories hence they can produce themes which can't be thought of by the earlier writers or the non-teenage novel writers. Second, teenage novels also imply the need for finding teenage identity in whatever genre the novel is written. Third, technology development and the modern world has become the particular soul for teenage novel. The writer and the readers are both very familiar with the development of technology such as cellphone, computer; as well as the development of the globalization such as internet, mall, along with the problems following it such as global warming, virtual crime, etc.

The language style used in teenage novels are the reflection of teenage lives as they are written for teenagers. Non formal utterances along with code mixing and code switching characterize the language used in the novels. Thus, it is very common to find English utterances in the form of words, phrases, clauses, or other meaningful expressions.

\section{Method}

This study is a descriptive research as this study describes the data gathered qualitatively. The data analyzed are taken from two teenage novels Balada Si Roy: Joe written by Gol A Gong which is written by in 1988 and republished in 2018 and Ruang Hampa Prada written by a group of writers in 2018. The population focused in this study are all of the utterances in the novels, and the samples are the utterances written in English including words, phrase, clausa, or other meaningful expressions. The analysis is conducted with the purpose to get insight of the function of English utterances in the novels.

\section{Result and Discussion}

\subsection{Language Analysis of the Novels}

The study is conducted by examining English utterances in two teenage novels, Balada Si Roy: Joe, and Ruang Hampa Prada. Balada Si Roy: Joe is written by Gong [1], and for this study the novel analyzed is the one reprinted in 2018. Therefore, the setting and the situation highly depict the situation of the 1980s. This novel tells the story of a boy named Roy who has to move to Bandung from Jakarta. He faces a lot of problems with his school's life, friends and life's goals. Ruang Hampa Prada is written by Aisyahra et al, 2018. Telling story about high school's student's life, this novel also evolves in school's life, friendship, love, and expectancy in teenagers' lives. As it is written in 2018, the setting and the situation also describe most of the present situation.

\subsection{English Utterances Used in the Novels}

\subsubsection{The Use of Words or Phrase}

In both novels, it can easily be found the use of English words or phrase. The most found category is the use of words which define the exact meaning of its original words. In other 
words, such words are borrowed from the source language (English). Such words or phrase are those related with musical instruments such as "Headphone, Walkman, groupies, rock star, rocker, breakdance, tape deck" [1]; "House music, hip hop, techno, electro, breakbeat, DJ pit" [2]. Looking at the era of its writing, it is obvious that the different type of music influences the life of teenagers, although both data from two different novels show that such words are kept in the original forms due to the difficulties in translating it in Bahasa Indonesia. With the same reasons some words associated with the world of sports such as "bowling, baseball, serve, out, smash overhead, drop shot" [1] are also borrowed literally. The use of English words in that sense does not show the ability to communicate in English, although the use of such particular register shows that the writer wants to describe his readers as those who are familiar with the sports or music's associated with such register.

There are also English words/phrase that are quite common and are used in this novel. The following examples are taken from both novels.

"Department store, blue jeans, cineplex, hardtop, coboy, escalator, lift, weekend, cottage, make up, cat walk, macho, T-shirt, best seller, thanks" [1].

"Please, monster, alien, basecamp, video game, honey, single, jackpot" [2].

Those words are very common to be used even in daily life, and there is no need to explain the meaning or even to translate it in Bahasa Indonesia.

Some peculiar words use within this context is the word "filter" and "standing" [1]. When they are translated literary, we should understand that these words can be translated actually. However, when the word in used within a particular context then we will find no reason but to use it as it is. The word "filter" stays with its original form as it is used with the meaning of filtered cigarette or in Bahasa Indonesia it is commonly mentioned as "rokok filter", while the word "standing" comes along with the meaning of doing a standing position, and therefore the translated meaning will be difficult to find.

The following words/phrase are quite common to be used in Bahasa Indonesia context, and yet it has its equivalent in Bahasa Indonesia. In Balada si Roy we can find for example, "sense of humor" with selera humor, "ice cream" with es krim, "falling in love" with jatuh cinta [1]. In Ruang Hampa Prada we can find "secret admirer" with pengagum rahasia, "sweet moment" with kesempatan indah, "hang out" with nongkrong [2]. One of the probable reasons for keeping the phrase in its original form is that such phrases create different sense in experiencing the meaning. The phrase hangout may suggest different experience than saying the word nongkrong.

The same reasons also applied in the use of many other words such as "bullshit, fans, weekend, free, girlfriend, jogging" [1]; "dress up, fresh, update" [2]. Although those words have their equivalent in Bahasa Indonesia, its original form suggests different connotation in meaning. The curse word "bullshit", for example, should share similar meaning with the Indonesian curse word such as sialan. However, there is a slightly different connotation meaning in saying bullshit which sound less harsh and yet express the anger appropriately.

There are also some words that are borrowed with particular affix from Javanese language, such as "ngebrik, ngedrug and nge DJ" [1] with the purpose to make an action verb out of English noun. In Balada Si Roy we can also find the phrase "married by accident" [1] which is English phrase but it is not commonly used as an English expression. Instead, it is a common expression in Bahasa Indonesia suggesting the meaning that the girl is already pregnant before she gets married. Also, we can find the word "gambling" [1], which is an English word but the meaning is not to gamble, or the state of gambling, but it is meant to say 
the meaning of taking a risk, which is actually in the basic sense similar with 'gambling'. In Ruang Hampa Prada, we can find the word "mameen" [2] which means actually as "my man'. Such expression is quite common in today teenagers, and in fact it is commonly used as one way of greetings as well.

There are also some case of word adjustment said by characters in both novels. The words "happy-happy" as in "yang penting happy happy saja" in Balada si Roy [1] and "sori sori" in Ruang Hampa Praha [2] suggest the adjustment use of the word happy and sorry which is actually an adjective to state it as noun with repetition indicating plural noun in Bahasa Indonesia grammar.

The sense of modernity is shown by the used of particular words in English such as "traveling, cafe, adventurer, appointment, cognac, road race" in Balada Si Roy [1]; "halter crop top, hot pants, skinny jeans, boot, sneakers, vending machine" in Ruang Hampa Prada [2].

\subsubsection{The Use of Meaningful Expression}

In addition to the use of words and phrase, there are also many English expression mentioned in both novels such as:

"No problem, happy sweet seventeen, so long, Home sweet home, happy new year, to the point, oh God, Come on, Oh my God, go ahead, poor boy, the haves" [1];

"Hay babe, at least, deal, yeah right, anyway, big no" [2].

Those expressions are considered as common expression in English; hence to use it a long with Bahasa Indonesia becomes quite common as well. Some of the expressions such as no problem, to the point, oh my God has become so common that there is no difficulty in saying it with the appropriated context.

Some of the expressions are considered more appropriate with teenagers' context rather than saying it in Bahasa Indonesia. For example, the expression of "happy sweet seventeen" [1]. In the 1980s being seventeen was associated with the beginning of being adult, where the girl (mostly) was allowed to have driving license, to go to the cinema, and even to get married, and therefore this age was considered as a special age that giving a salutation happy sweet seventeen was believed to be more appropriate.

\subsubsection{The Use of Clause}

There are only a few of clauses written in both novels. In Balada Si Roy most of the clauses written are the excerpts taken from the songs or famous quotes. The examples of the excerpt from the songs are "Jump!, go ahead jump; I don't like Monday; Light my fire; Come on baby, light my fire" [1]. The examples of popular quotes are taken from Balada Si Roy as follows:

“Girl, we couldn't get much higher, come on my baby, light my fire; We columbine together; You may say I am a dreamer; What's in a name? That which we call a rose by other name would smell as sweet; You are what you eat, you talk what you read" [1]. 
On the other hand, we couldn't find such excerpt or quotes in Ruang Hampa Prada. The use of such clause in the text does not show the ability for being multilingual in English, because how the sentences are structured does not show the genuine ability to switch code [14]. In other words, it is difficult to see if the writer or the expected readers are able to construct meaningful correct clause in English. However, the fact that the writer is able to put many different excerpts or quotes in the text shows that the writer wants to show that his expected readers are familiar with English text in the songs. This suggests that although the readers are perhaps not expected to be able to communicate in English actively, they are able to communicate it passively.

Another type of clauses written in both novels are the real clauses produced by the writer. In Balada Si Roy we can find

"See you, Tomboy; Are you okay, Roy; fight is a fight; Say something, Roy; Look like a movie star!; The show must go on; How about Tony?; See you tomorrow"; Go to hell" [1].

In Ruang Hampa Prada we can find:

"He's cute and smart; Don't be afraid, I am here; What?; You're moron; It's okay Kar; It's creepy as hell; OK, So here is the truth; Yeah, that's sucks" [2].

Most of the clauses written above are the ones which are quite popular as expressions. Are you okay? see you; see you tomorrow; it's okay are common clauses frequently mentioned in movies, novels, or mentioned by the radio announcers. Due to those reasons, it is also difficult to suggest that the teenagers reading the novels are considered as having multilingual ability in English. Nevertheless, some other sentences also suggest that the teenagers in fact have such ability at particular extent. Although it is simple, the sentence such as "fight is a fight" [1] and "look like a movie star" [1] suggests that the teenagers are able to switch to English. A more complex sentence such as "It's creepy as hell" [1] and "So here is the truth" [2] shows better development of English competence in teenagers.

\subsection{Culture and Ideological Background}

The novels are written in two different time frames. Thus, we can see the cultural background underlined the situation. In Balada Si Roy the setting of 1980s has great influence on the novels. The popularity of American music's and rock bands has their own place in the teenage lives back then. There are many rock bands referred by the author of the novels such as "The Beatles, The Animal, Deep Purple, Led Zeppelin, The Doors, Super Kid, The Rolling Stone, The Rallies, Deep Purples" [1] and others. Popular singers or musicians also mentioned along with their hits such as "John Lennon, Debbie Gibson, Jim Morrison, Michael Jackson, Johnny Winter, Van Hellen” [1].

In addition to that, TV shows, movies, and books also play parts in the teenagers' lives. "Borsalino, The Outsiders, Jungle Jim" [1] were the names of the movies and TV show that were believed to be popular in teenage lives in that era. The fact that the writer does not even give the explanation of what kind of movies it shows that among the teenagers, such movies were quite popular and that it is easy to refer to them. Popular novel such as "Romeo Juliet" [1] and "Around the World in 80 Days" [1] are also introduced by the writer, may be because both novels depict the philosophy and goals of Roy, the central character of Balada Si Roy. 
Roy's frequently broken heart is associated with the pain of the story in Romeo and Juliet and Roy's dream to have adventure around the world is referred to Jules Verne's Novel Around the World in 80 days.

In Ruang Hampa Prada the song that is mentioned by the writers is the one from South Korea such as "Kiss the Rain" [2]. Although it is titled in English, it is actually written by a song writer from Korea. The movie associated with the life of teenagers is exemplified by "Beauty and The Beast" [2], a Disney fairy tale story supposedly targeted for early age of teenagers. The use of social media is also highlighted by mentioning common registers such as selebgram, selebtwitt, wallpaper lock screen, posting, and followers.

Overall the characters in Balada Si Roy are depicted as more mature than the characters in Ruang Hampa Prada although they are actually in the same stage of life, as the students of high schools. The choice of movies for example. In Balada Si Roy, the high schools' students watch gangster movie, while in Ruang Hampa Prada the high school students watch fairy tales.

Roy and his friends are also depicted as teenage boys who dare to do dangerous things such as racing on the street, and do other adult things such as making their own income, while the girls are depicted as those who are ready to start a family after finishing high schools. The romance scene is also described as being bold, with the reference of activities showing more intimate relationship such as kissing the lips, or referring to body parts that are quite sensitive, such as thigh or breast.

In Ruang Hampa Prada the characters are depicted as those who are not quite mature with common naughtiness like playing truant, or bullying friends. The romance scene is described as the kids having closer relationship, such as holding hands, or studying together.

\section{Conclusion}

The use of words, phrase, meaningful expression and clause are quite abundant in both novels, suggesting that the writer and intended readers are familiar with such utterances in English, especially in Balada Si Roy where more references of English words are used. This is also supported by the fact that the characters are familiar with the many music, movies, and books written in English and depicting the American culture. However, the study finds only a little evidence showing that the characters are multilinguals in English due to the fact that most of the English utterances mentioned in both novels are actually common expressions frequently found in books, or mentioned in movies or by radio announcers. The American English highly influenced Balada si Roy, while in Ruang Hampa Prada, the modernity is shown more along with the influence of South Korea. Still, English exposure throughout several decades has shown a better progress of language learning and the familiarity of culture as well.

\section{References}

[1] G. A. Gong, Balada Si Roy. Jakarta: Gramedia Pustaka Utama, 2018.

[2] V. Aisyahra, Dwipatra, L. Nurida, A. Natanel, and H. Namire, Ruang Hampa Prada. Jakarta: Gramedia Pustaka Utama, 2018.

[3] D. Lyons., "A brief History of English," 2017.

[4] U. Sulistio, "The Influence of English as Global Language on English Teaching Practices," $J$. 
Univ. Batanghari, 2012.

[5] J. S. Lee, "Linguistic constructions of modernity: English mixing in Korean television commercials," Lang. Soc., vol. 35, no. 1, pp. 59-91, 2006.

[6] C. L. Hallen, "Language Contact and Its Influence in Bahasa Indonesia's Phonemic System," 1999. .

[7] O. Komaria, "The History of English Language Teaching in Indonesia," Unpubl. Master Thesis - UNIKA Atmajaya, 2007.

[8] J. Harmer, "English language teaching," Harlow Pearson Educ. Ltd., 2001.

[9] H. D. Brown, Principles of language learning and teaching, vol. 4. Longman New York, 2000.

[10] J. Holmes, An Introduction to Sociolinguistics. England: Pearson Education Ltd., 2001.

[11] C. A. Alwasilah, Perspectif Pengajaran Bahasa Inggris di Indonesia dalam Konteks Persaingan Global. Bandung: Andira, 2000.

[12] M. Violine, "Gaya Bahasa Teenlit: Pilihan dan Pembentukan Kata," 2009. .

[13] J. S. Kaplan, "Young adult literature in the 21st century: Moving beyond traditional constraints and conventions," Alan Rev., vol. 32, no. 2, p. 11, 2005.

[14] R. Hanafiah, A. Rantika, and M. Yusuf, "The Levels of English-Arabic Code-Mixing in Islamic Boarding School Students' Daily Conversation,” Adv. Lang. Lit. Stud., vol. 9, no. 6, pp. 78-81, 2018. 